\title{
Retrieving mesospheric water vapour from observations of volume scattering radiances
}

\author{
P. Vergados ${ }^{1}$ and M. G. Shepherd ${ }^{2}$ \\ ${ }^{1}$ Department of Physics and Astronomy, York University, Toronto, Ontario, Canada \\ ${ }^{2}$ Centre for Research in Earth and Space Science, York University, Toronto, Ontario, Canada
}

Received: 29 April 2008 - Revised: 4 November 2008 - Accepted: 16 December 2008 - Published: 2 February 2009

\begin{abstract}
This study examines the possibility for a theoretical approach in the estimation of water vapour mixing ratios in the vicinity of polar mesospheric clouds (PMC) using satellite observations of Volume Scattering Radiances (VSR) obtained at the wavelength of $553 \mathrm{~nm}$. The PMC scattering properties perturb the underlying molecular Rayleigh scattered solar radiance of the background atmosphere. As a result, the presence of PMC leads to an enhancement in the observed VSR at the altitude of the layer; the PMC VSRs are superimposed on the exponentially decreasing with height Rayleigh VSR, of the PMC-free atmosphere. The ratio between the observed and the Rayleigh VSR of the background atmosphere is used to simulate the environment in which the cloud layer is formed. In addition, a microphysical model of ice particle formation is employed to predict the PMC VSRs. The initial water vapour profile is perturbed until the modelled VSRs match the observed, at which point the corresponding temperature and water vapour profiles can be considered as a first approximation of those describing the atmosphere at the time of the observations. The role of temperature and water vapour in the cloud formation is examined by a number of sensitivity tests suggesting that the water vapour plays a dominant role in the cloud formation in agreement with experimental results. The estimated water vapour profiles are compared with independent observations to examine the model capability in the context of this study. The results obtained are in a good agreement at the peak of the PMC layer although the radiance rapidly decreases with height below the peak. This simplified scenario indicates that the technique employed can give a first approximation estimate of the water vapour mixing ratio, giving rise to the VSR observed in the presence of PMC.
\end{abstract}

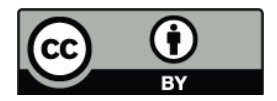

Correspondence to: M. G. Shepherd (mshepher@yorku.ca)
Keywords. Atmospheric composition and structure (Aerosols and particles; Middle atmosphere - composition and chemistry; General or miscellaneous)

\section{Introduction}

The phenomenon of noctilucent clouds (NLC) was first observed in the late 1880-ies at twilight in summer time at Northern high latitudes and reported by Backhouse (1885) and Jesse (1887). Jesse (1887) determined the average altitude of NLC at $\sim 82 \mathrm{~km}$, confined to a geometrically thin layer of typically 1-3 km (Thomas, 1991, and the references therein). Since then there have been extensive observations and modelling efforts to determine the origin, morphology and microphysical properties of these clouds employing both ground-based and satellite means (e.g. Thomas, 1991; von Zahn and Berger, 2003; DeLand et al., 2003, Rapp and Thomas, 2006, and references therein, to mention some of the more recent studies).

The first observations of NLCs from space were performed by the Orbiting Geophysical Observatory (OGO6) in 1970 (Donahue et al., 1972); it was suggested they be called Polar Mesospheric Clouds (PMC) to characterize these space-based observations (Thomas, 1995). Since then, extensive observations of PMC have been made by various satellite experiments, among which the Ultra-Violet Spectrometer (UVS) on board the Solar Mesosphere Explorer (SME) (Olivero and Thomas, 1986; Thomas and Olivero, 1989), the Solar Backscattered Ultraviolet (SBUV) instrument on Nimbus-7 (Thomas, 1991), the Wind Imaging Interferometer (WINDII) (Evans et al., 1995) and the Halogen Occultation Experiment (HALOE) (Hervig et al., 2001; Hervig et al., 2003) on the Upper Atmosphere Research Satellite (UARS) (Reber et al., 1993), and the Polar Ozone

Published by Copernicus Publications on behalf of the European Geosciences Union. 
and Aerosol Measurement (POAM II) (Debrestian et al., 1997). More recently PMC observations were performed by the Student Nitric Oxygen Experiment (SNOE) (Bailey et al., 2005), the Optical Spectrograph and InfraRed Imaging System (OSIRIS)/Odin experiment (Murtagh et al., 2002; von Savigny et al., 2005; Petelina et al., 2006), the Scanning Imaging Absorpton spectrometer for Atmospheric CHartography (SCIAMACHY) on ENVISAT (Bovensmann et al., 1999; von Savigny et al., 2004), the Atmospheric Chemistry Experiment (ACE) (Bernath, 2001; Bernath et al., 2005), and the Aeronomy of Ice in the Mesosphere (AIM) experiment (Russell et al., 2009; Benze et al., 2009; Hervig et al., 2009). However, there are still remaining questions about the PMCs formation mechanism, evolution, physical properties and composition. Ground-based and satellite observations aim at answering these questions by studying the clouds' physical properties and measuring the thermal, chemical and dynamical environment in which they form.

It is now well accepted that PMC can be described as a thin layer, located near the high-latitude summer mesopause region in both hemispheres, comprised of ice or iced (icecoated) particles (Reid, 1997; von Cossart et al., 1997, 1999; Hervig et al., 2001; Emerenko et al., 2005). The current theoretical understanding of the microphysics, life cycle and brightness of PMC layers indicates that the ambient temperature and water vapour mixing ratio control the formation and evolution of these layers (e.g. Turco et al., 1982; Thomas, 1991; Lübken, 1999; von Zahn et al., 2004). In this regard, ambient temperature, water vapour mixing ratio and volume scattering radiance measurements may be considered as PMC parameters. However, the point to be made in the current study is the possibility to use VSR measurements in the altitude range $70-90 \mathrm{~km}$ in the presence of PMC for the calculation of back-scatter ratio (BSR, defined in Sect. 2.5) profiles, in order to derive in turn an estimate of water vapour content in the mesosphere and in the vicinity of PMC, using a microphysical model. This topic is discussed in more detail in the following order. First, the methodology and theoretical approximations considered in the present study are described. The microphysical model is employed in examining the dependence of PMC's BSR on the ambient temperature and water vapour mixing ratio. Next, the model predictions are compared with independent observations and the results obtained are discussed.

\section{Methodology}

\subsection{General description of the technique}

The idea of using a theoretical approach in the estimation of atmospheric parameters in the PMC region (such as temperature or water vapour mixing ratio) will be illustrated employing volume scattering radiances (VSR) observed from a limb viewing of the atmosphere in the vicinity of the mesopause.
This paper reports an attempt to develop a method, in which satellite BSR profiles of PMC and VSR can be used in combination with a $1-\mathrm{D}$ version of the Community Aerosol and Radiation Model for Atmospheres (CARMA) (Turco et al., 1979; Toon et al., 1979), in order to derive a self-consistent measure of the water vapour mixing ratio in the vicinity of these PMC.

On the one hand, the PMC detection process used in this work takes advantage of the enhancement of the VSR of the solar radiance measured. PMC can be identified in satellite observations as an enhancement in the volume scattering radiances (VSR) of the measured solar radiance at the altitude of the cloud formation superimposed on the Rayleigh (exponentially decreasing with height) VSR of the cloud-free atmosphere.

On the other hand, for the modelling effort of PMC layers, the CARMA model requires initialization of the conditions of the ambient atmosphere (such as temperature and water vapour mixing ratio). For the purpose of the analysis, temperature data obtained from Falling Sphere (FS) experiments (Schmidlin et al., 1991) are used in the altitude range from 70 to $90 \mathrm{~km}$ height. Water vapour mixing ratio profiles, used for the initialization of the model simulations (herein called "reference profiles"), are adopted from the HALOE v. 19 experiments (Russell et al., 1993) on the UARS. In addition, the CARMA model was modified to calculate the BSR profile of the simulated PMC.

Two sets of BSR profiles are obtained: experimental (WINDII) and modelled (CARMA). During the simulation process, the observed and the modelled BSR profiles are compared. When the modelled BSR profile becomes comparable or matches the observed BSR profile, the water vapour mixing ratio profile is recorded. Finally, the derived water vapour mixing ratios are compared with independent satellite observations to verify the results obtained.

\subsection{Satellite-based PMC observations by the WINDII experiment}

Vertical profiles of the BSR in the height range 70 to $90 \mathrm{~km}$ are derived from the Wind Imaging Interferometer (WINDII) (Shepherd et al., 1993) observations of Volume Rayleigh Scattering Radiance (VRSR). WINDII was primarily designed to measure global winds, by measuring the wavelength shift of visible airglow emission lines. The WINDII volume scattering radiances (VSR) are obtained from the green-line $\mathrm{O}\left({ }^{1} \mathrm{~S}\right)$ background filter at a wavelength of $553 \mathrm{~nm}$. The radiance detected by the instrument is predominantly scattered solar radiation from the atmospheric molecules, thus having a Rayleigh-type exponential distribution with height, and is used to derive back-scatter ratios (Evans et al., 1995) and mesospheric temperatures (Shepherd et al., 2001). Since the WINDII temperatures are derived from the Rayleigh scattering radiances in the presence of PMCs no temperature measurements are possible within 
the PMCs as the scattered light is distorted from its exponential profile. The BSR are interpreted as a signature of the presence of PMCs. The PMC signatures came as a by-product of the VSR observations, appearing as sharp intensity enhancements on the Rayleigh scattered atmospheric background at altitudes of $\sim 83-85 \mathrm{~km}$ in the summer atmosphere. The BSRs, obtained as the ratio between the observed VSR and the VSR corresponding to the Rayleigh scattering background at $553 \mathrm{~nm}$ wavelength, and their vertical extent give information on the cloud brightness and its thickness. The vertical resolution of WINDII VSR data, from which temperature and BSR are derived, is $2 \mathrm{~km}$ in the height range 65 to $115 \mathrm{~km}$. More information on the WINDII experiment can be found elsewhere (Shepherd et al., 1993). About 45 data profiles of VSR are observed per day within a $10^{\circ}$ latitudinal band, which allows the mapping of the PMC and their brightness at high latitudes $\left(>55^{\circ}\right)$ in both hemispheres.

\subsection{The 1-D CARMA model}

The CARMA model is a multi-dimensional model for aerosols (Toon et al., 1988), and uses Eulerian transport of dust and ice particles to simulate the formation and evolution of PMC particles and layers. It has been widely used in the study of the microphysical and physical properties of PMC (e.g. Turco et al., 1982; Jensen and Thomas, 1988; Jensen et al., 1989; Rapp et al., 2002, 2007; Rapp and Thomas, 2006). In the scope of the present study, dust and ice particles are modelled at a latitude of $\sim 69^{\circ} \mathrm{N}$ for the altitude range from 75 to $90 \mathrm{~km}$. The CARMA model used in its 1-D version accounts only for vertical transport. Neither additional influxes of meteoric dust particles at the top of the model domain nor water vapour influx from below (except from the original initialization) are assumed. Condensation nuclei are presumed to exist in altitude and size distributions according to the model of Hunten et al. (1980). The meteoric dust particle size distribution is assumed to be a log-normal (Turco et al., 1982; Toon et al., 1988). The log-normal size distribution was defined by defining its median radius, total particle number density and geometric standard deviation. The median radius of these particles varies from $0.9 \mathrm{~nm}$ at $86 \mathrm{~km}$ to $3 \mathrm{~nm}$ at $84 \mathrm{~km}$ height, while the total particle number density varies between $2500 \mathrm{~cm}^{-3}$ at $86 \mathrm{~km}$ to $3250 \mathrm{~cm}^{-3}$ at $84 \mathrm{~km}$. PMC ice particles are formed via heterogeneous nucleation on preexisting dust particles. Although there is no real proof of the kind of nucleation mechanism responsible for the PMC particle formation, the assumption of heterogeneous nucleation is considered to be a useful tool for the modelling of PMC layers, and serves the purpose of this research, because ice particles are formed either by a) homogeneous, b) heterogeneous, or c) ion nucleation. The ice particles formed during the nucleation and growth processes have to overcome the Kelvin barrier of the Gibbs free energy of the particle-water vapour system in order to be stable and keep growing (e.g. Gadsden and Schröder, 1989). Reid (1997), having studied the nucleation and growth of ice particles in the upper mesosphere, points out that the nucleation on dust particles is a far more efficient nucleation process than the ion nucleation, while Gumbel et al. (2003) found that homogeneous or ion nucleation does not play a significant role in the formation of ice particles near the summer mesopause. This result is also supported by von Zahn and Berger (2003), who found that the respective super-saturation ratios for homogeneous and ion nucleation, needed for stable growth of pure ice crystals in the upper mesosphere region, are of the order of 1000 and 200 , respectively. Hence, at least from a theoretical point of view, heterogeneous nucleation on nanometer-sized particles appears to be an efficient and significant process of nucleation (e.g. von Zahn and Berger, 2003).

As the present study is not primarily a model development project, the dependence of PMC particle formation on fundamental microphysical parameters, such as nucleation, is not examined; rather we allow some empiricism in the model. In this context the sensitivity of the back-scatter ratio at the peak of PMC layers $(\sim 83 \mathrm{~km})$ to temperature and water vapour mixing ratio perturbations is examined using a 1-D version of the CARMA model. To this end, the forward model calculates the PMC BSR from assumed initial temperature and water vapour profiles estimating the BSR evolution over a period of $48 \mathrm{~h}$. These calculations are repeated for a number of cases, in which the initial water vapour mixing ratio and temperature profiles are scaled up and down by $\pm 1.0 \mathrm{ppmv}$ and \pm 2.0 ppmv, and $\pm 5 \%(\sim 7 \mathrm{~K})$, respectively. Some of the results from these simulations are presented and discussed in Sect. 3. The vertical profile of the eddy diffusion coefficient used in this study is adopted from von Zahn and Berger (2003) and corresponds to summer conditions at the Arctic Lidar Observatory for Middle Atmosphere Research (ALOMAR) (e.g. Lübken, 1997). The eddy diffusion coefficient increases with increasing altitude above $82 \mathrm{~km}$, obtaining its maximum value around $87 \mathrm{~km}\left(1.2 \times 10^{6} \mathrm{~cm}^{2} \mathrm{~s}^{-1}\right)$. Below $82 \mathrm{~km}$, it takes a constant value of $10^{4} \mathrm{~cm}^{2} \mathrm{~s}^{-1}$.

\subsection{Model initialization}

Falling-sphere (FS) experiments have been previously used for the study of the thermal structure of the Arctic summer mesosphere (e.g. Lübken, 1999). Unlike remote sensing techniques, they provide in-situ measurements of the atmospheric density and temperature and are proven to be a valuable technique in measuring temperature within PMC displays. The initialization temperature profile employed in the CARMA model is the mean of 15 FS profiles obtained between 27 July and 17 August 1992 during the SCALE and ECHO campaigns at Andoya $\left(69^{\circ} \mathrm{N}, 16^{\circ} \mathrm{E}\right)$ (Lübken, 1999; A. Mülleman, personal communication, 2002). The mean temperature profile over this period can be considered as a representation of the mean thermal structure of the summer mesosphere in early August 1992, the period for which there are also VSR and BSR satellite observations from WINDII 
at Northern high latitude. Lübken (2000) reported that the mean temperature at typical PMC altitudes, from the beginning of June until mid-August, remains rather constant with time, but changes significantly by $5-10 \mathrm{~K}$ before and after that period. Under these circumstances, the mean FS temperature profile selected is considered to be a good approximation for the initialization of the CARMA model for PMC BSR simulations in late July/early August 1992. At the time of the WINDII BSR observations the only observations of water vapour mixing ratios close in time and space to WINDII came from the HALOE experiment on UARS. Hence, the selection of that data as a "reference source" of water vapour mixing ratio serves as an approximation in the model initialization.

The two UARS instruments, WINDII and HALOE, look in different directions and do not observe simultaneously the same volume of air. Therefore at a first glance it seems that the combination of WINDII and HALOE observations is not very appropriate. However, the purpose of this study is to describe and demonstrate how water vapour (temperature) profiles can be estimated having knowledge of the BSR and temperature (water vapour) profiles associated with the presence of PMC. For this purpose it is sufficient that both WINDII and HALOE experiments observe the upper mesosphere at high latitudes during the PMC season, and can provide information about the water vapour mixing ratio and the presence of PMC.

\subsection{Theoretical considerations in the modelling of the BSR}

In the presence of PMC, the volume scattering radiance measured by the WINDII experiment $\left(\mathrm{VSR}_{m}\right)$ departs from the exponentially distributed with height background volume Rayleigh scattering radiance (VRSR). The ratio between the $\mathrm{VSR}_{m}$ and the VSR of the background atmosphere gives a measure of how much brighter the PMC is compared to the background and can be expressed as:

$$
\begin{aligned}
& \mathrm{VSR}_{m}=\mathrm{VRSR}_{a}+\mathrm{VSR}_{\mathrm{PMC}}, \\
& R=\frac{\mathrm{VSR}_{m}}{\operatorname{VRSR}_{a}}=1+\frac{\mathrm{VSR}_{\mathrm{PMC}}}{\operatorname{VRSR}_{a}},
\end{aligned}
$$

where $\mathrm{VSR}_{m}$ is the WINDII-measured volume scattering radiance, VSR $_{\mathrm{PMC}}$ is the volume scattering radiance of the $\mathrm{PMC}$, and $\mathrm{VRSR}_{a}$ is the volume Rayleigh scattering radiance of the cloud-free atmosphere, in photons $\mathrm{cm}^{-3} \mathrm{~s}^{-1}$; the ratio $R$ is dimensionless and does not depend on the Sun's radiance or instrument sensitivity. Here only the quantity $\mathrm{VSR}_{m}$ is measured. The value of $\mathrm{VRSR}_{a}$ is found from the area where $\mathrm{VSR}_{m}=\mathrm{VRSR}_{a}$, that is below and above the PMC layer. An exponential fit to that area is applied and extrapolated over the height range from 75 to $90 \mathrm{~km}$, thus obtaining the $\operatorname{VRSR}_{a}$. The ratio $R$ is equal to unity when no PMC are present.
Recent optical studies of NLC ice particle size distributions, at visible wavelengths ( $440 \mathrm{~nm}$ and greater) (Hedin et al., 2008, Fig. 3) have shown that the scattering of light by typical PMC particles is very close to Rayleigh-type, if the particles are spherical. In the case of WINDII with observations at $553 \mathrm{~nm}$ wavelength this concerns the consideration of the Rayleigh scattering of PMC particles adopted in the study conducted. Although particle scattering theory based on the size of individual particles could be applied to such a study, before employing more complex theories (e.g. Miescattering theory) in the analysis, we consider it necessary to examine the results using Rayleigh scattering. Therefore, at this point of our proposed approach, we try to construct, describe and explain the basic steps that need be considered in order to retrieve water vapour profiles in the vicinity of PMC from the WINDII BSR observations. At the WINDII observations wavelength of $553 \mathrm{~nm}$, the Rayleigh-limit is reached even earlier than at $440 \mathrm{~nm}$ wavelength (the wavelength considered by Hedin et al., 2008) and thus Rayleigh scattering theory describes satisfactory the scattering properties of the ice particle size distribution considered in the current study. In the process of simulating the BSR with the 1-D CARMA model we have adopted the method by Klostermeyer (1998), where the total scattering ratio $R^{\prime}$ of the atmosphere is expressed in terms of the total extinction coefficient of the scattering medium (the iced particles) $\gamma_{i}$ and the air $\gamma_{a}$, as:

$R^{\prime}=1.0+\frac{\gamma_{i}}{\gamma_{a}}$.

With an accuracy of $\sim 10 \%, R^{\prime}$ is also an estimate of the BSR (Klostermeyer, 1998). The total extinction coefficient $\gamma_{i}$ of iced particles at the wavelength $\lambda(\lambda=553 \mathrm{~nm}$ for the WINDII $\mathrm{VSR}_{m}$ observations) equals the sum of the scattering cross sections of the individual molecules per $\mathrm{cm}^{3}$ and is given as:

$\gamma_{i}=\int \pi r^{2} Q_{r}(d n / d r) \cdot d r$

where $r$ is the particle radius in centimetres, $Q_{r}$ is the efficiency factor of each particle size and $d n(r)$ is the particle number density at each size bin of radius $r$ expressed in $\mathrm{cm}^{-3}$. For particle radii of less than $80 \mathrm{~nm}, Q_{r}$ can be expressed analytically by the first term of a series expansion (van de Hulst, 1957, p. 144; Klostermeyer, 1998) and is given by:

$Q(r)=\frac{8}{3} \cdot x^{4}\left(\frac{m^{2}-1}{m^{2}+2}\right)^{2}$,

where $m$ is the refractive index of the medium (iced particles) and $x$ is the "size parameter", $\left(x=\frac{2 \pi r}{\lambda}\right)$. Although we have assumed heterogeneous nucleation of iced particles with a silicon-based dust core, the refractive index used in Eq. (5) is that of water ice, since the resulting particles are ice-coated. Although this assumption may generate a systematic error in our results, it is sufficient for the purpose of this study. 
Another issue rises when choosing the value of the refractive index of water ice at mesopause temperatures. Although the refractive index of water ice is not well known at such low temperatures, Westley et al. (1998) measured its value to be $1.29 \pm 0.01$ at temperatures below $142 \mathrm{~K}$; this value is used in the present study.

The values of the $d n(r)$ are provided by the model simulations. Substituting Eq. (5) in Eq. (4) gives the total scattering cross-section of the cloud layer as a function of altitude. The log-normal particle size distribution was chosen, since is the most commonly used size distribution in model simulations. For our case, the resulting log-normal size distribution of the iced particles obtains a median radius range between 20 and $35 \mathrm{~nm}$ with a width of 1.4. Thus, the size parameter for each case considered falls between 0.22 and 0.39 .

For the estimation of $R^{\prime}$ the molecular extinction coefficient of the air need be calculated as well. However, due to the lack of data for the molecular extinction coefficient from the WINDII measurements, an alternative method had to be considered. In the case of WINDII, the observations are made at the limb, away from the sun and are dependent on the solar zenith angle, which is also related to the position of the satellite and the local solar time (LST) at the time of the observations. A review of the range of LST observed for the cases considered shows a mean scattering angle of $\frac{3}{4} \pi$ $\left(135^{\circ}\right)$. Therefore, the molecular extinction coefficient of the air, $\gamma_{a}$ per unit volume is based on the Rayleigh theory and is given by:

$\gamma_{a}=N_{m} \cdot \frac{d \sigma\left(135^{\circ}\right)}{d \Omega}$,

where $\frac{d \sigma\left(135^{\circ}\right)}{d \Omega}$ is the differential Rayleigh scattering crosssection at scattering angle $\Theta=135^{\circ}$ per average gas molecule, expressed in $\mathrm{cm}^{2} \mathrm{sr}^{-1}, d \Omega$ is the increment of solid angle in the direction of radiance $\Omega$, while $N_{m}$ is the molecular number density given in molecules $\mathrm{cm}^{-3}$. Below $100 \mathrm{~km}$, the differential Rayleigh scattering cross section is calculated as (adapted from Collis and Russell, 1976, p. 89, Eq. $4.7^{1}$ ):

$\frac{d \sigma\left(135^{\circ}\right)}{d \Omega}=4.0875 \cdot\left(\frac{\lambda(\mu \mathrm{m})}{0.55}\right)^{-4} \cdot 10^{-28} \mathrm{~cm}^{2} \mathrm{sr}^{-1}$,

where $\lambda$ is the wavelength of observation and the molecular number density is given as:

$N_{m}=\frac{P(z)}{T(z)} \cdot \frac{N_{a}}{R_{a}}$

Here $P(z)$ and $T(z)$ are the pressure and temperature at altitude $z$, respectively; $N_{a}$ and $R_{a}$ are Avogadro's Number and the individual gas constant ${ }^{2}$ for the dry air, respectively. The

\footnotetext{
${ }^{1}$ In its original form Eq. (4.7) of Collins and Russell (1976) is presented for a scattering angle of $\Theta=\pi$, applicable for lidar observations, with a constant in front of the brackets of 5.45.

${ }^{2}$ The individual Gas Constant depends on the particular gas and is related to the molecular weight of the gas. The value is independent of temperature and for dry air $R_{a}=286.9 \mathrm{~J} / \mathrm{kg} \mathrm{K}$.
}

modelling simulations of the scattering ratio $R^{\prime}$ (which we call back-scatter ratio, adopting the term from Rayleigh lidar observations) are considered successful if the values of the measured scattering ratio $R$ and the modelled $R^{\prime}$ become comparable, or in the ideal case $R^{\prime} / R=1$. With this in mind, Eq. (7) provides an empirical relationship between the radiance wavelength and the differential Rayleigh-scattering cross-section and thus a convenient way of estimating the latter, thus allowing a first order approximation estimate of water vapour content from observations of VSRs in the presence of PMCs.

\section{Sensitivity test results}

A sensitivity test was performed to examine the degree to which variations in the background temperature and water vapour content affect the BSRs. For the purpose of this test, temperature and water vapour profiles correlative in time and space, that are in the height range from 70 to $90 \mathrm{~km}$ were required. These profiles are taken from the HALOE observations at $74^{\circ} \mathrm{N}$ on 24 August 1992. The mesopause is located at around $84 \mathrm{~km}$ with a temperature of $156 \mathrm{~K}$; the water vapour mixing ratio at that altitude is $4.7 \mathrm{ppmv}$. At this starting point the minimum temperature is well above the temperature of super-saturation and no PMCs were observed or could be simulated.

The sensitivity test proceeded by decreasing (scaling down) the temperature, while keeping the water vapour profile at its initial value and running the CARMA model until the critical point of supersaturation is reached, indicating the atmospheric conditions for which PMCs (iced particles) begin to form from the assumed background water vapour content. The model simulations showed that for the selected water vapour content iced particles begin to form at a mesopause temperature of $142 \mathrm{~K}$. Therefore the starting point of the sensitivity test is for a mesopause temperature of $142 \mathrm{~K}$ and water vapour of $4.7 \mathrm{ppmv}$. Scaling down this "reference" temperature profile by $5 \%$ and $10 \%$ led to temperatures of $135 \mathrm{~K}$ and $128 \mathrm{~K}$ respectively, at the mesopause, while the water vapour profile was kept unchanged from the initial assumption. The temperature profile with mesopause temperature of $135 \mathrm{~K}$ is assumed to be the sensitivity test's "base-line" profile. The decrease in the temperature leads to a broadening of the region of super-saturation, in which sedimenting particles have a larger background area, over which they can grow and sediment. Through the sedimentation process, the iced particles grow as water vapour from the background atmosphere deposits onto their surface, allowing larger particles to reside at the bottom of the clouds. It is therefore expected that the altitude peak of a PMC as observed through the BSR profile to be shifted to lower altitudes.

The effect of temperature variations on the PMC's BSR profiles is illustrated in Fig. 1a. The simulations begin with 

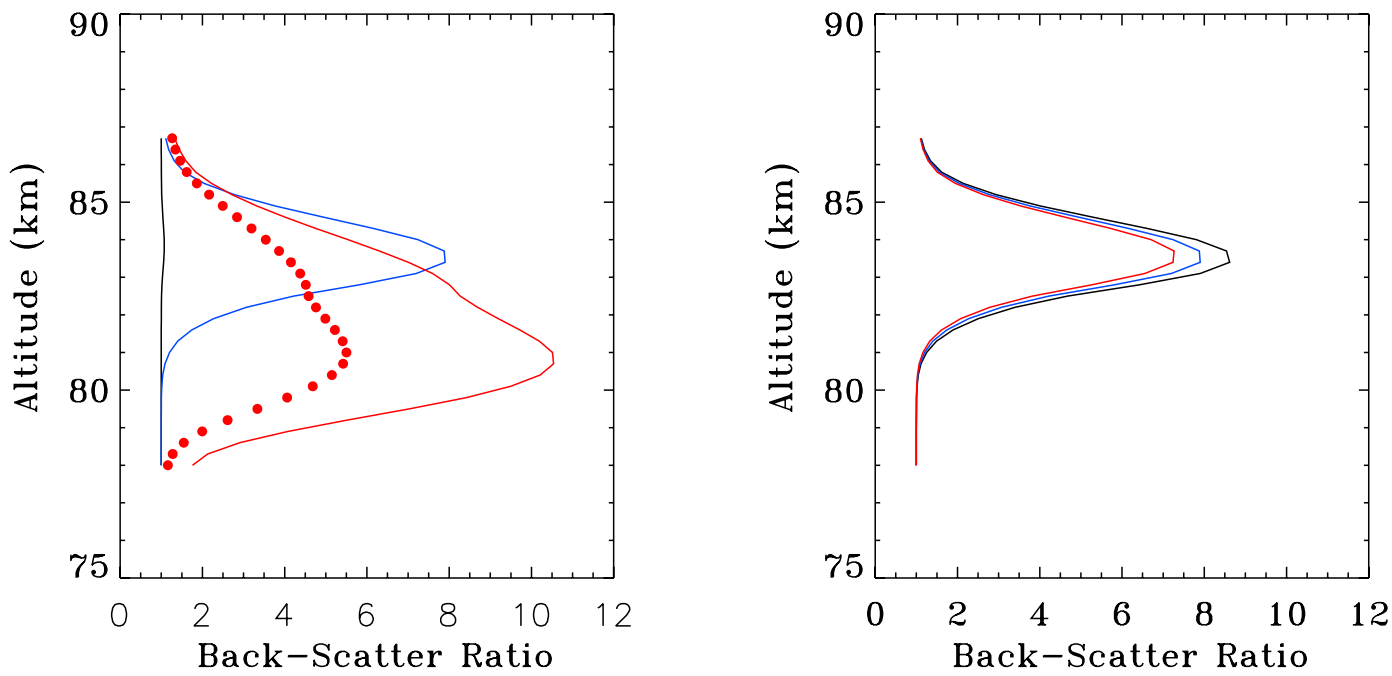

Fig. 1. BSR profiles at the time when the particle number density falls below $\sim 100 \mathrm{~cm}^{-3}$ due to variations in temperature and water vapour mixing ratio. (a) Reducing the "base-line" temperature, $T$, by $5 \%$ to $135 \mathrm{~K}$ (blue solid line), and by $10 \%$ to $128 \mathrm{~K}$ (red solid line); reducing $T$ by $10 \%$ to $128 \mathrm{~K}$ after $11 \mathrm{~h}$ of particle growth (red dotted line). The water vapour remains constant at 4.7 ppmv. (b) The BSR profile for a base-line water vapour mixing ratio of $4.7 \mathrm{ppmv}$ is given in blue. The BSR profiles corresponding to a $5 \%$ increase and $5 \%$ decrease in mixing ratio are given in black and red, respectively. The temperature is kept constant at $135 \mathrm{~K}$.

the reduction of the temperature by $5 \%$ and $10 \%$, while the water vapour profile is kept constant, yielding the BSR profiles presented in Fig. 1a. The super-saturation case (142 K) is given in black, the 5\% temperature reduction, corresponding to $135 \mathrm{~K}$ is given in blue, and the $10 \%$ temperature reduction corresponding to $128 \mathrm{~K}$ is given by the red solid line. Because the lifetime of iced particles varies with temperature, the lifetime of the modelled PMC under different mesopause temperatures is expected to vary as well. Thus, in order to compare the results obtained, the BSR profile values are recorded at the time when the cloud begins disappearing (i.e. when the cloud particle concentration falls below 100 particles $\mathrm{cm}^{-3}$ (von Zahn and Berger, 2003)). At $135 \mathrm{~K}$ the BSR reaches a value of 8 after $\sim 11 \mathrm{~h}$ from the beginning of the model simulation. An additional $7 \mathrm{~K}$ decrease in the temperature at $84 \mathrm{~km}$, from $135 \mathrm{~K}$ to $128 \mathrm{~K}$, leads to a broadening of the formed layer and a shift of the cloud peak to lower altitude. The BSR reaches a value of 11 after $\sim 27 \mathrm{~h}$ from the beginning of the model simulation (Fig. 1a, red solid line), corresponding to a $37.5 \%$ increase in the BSR. However, because the lifetime of the modelled PMC at $128 \mathrm{~K}$ is longer than at $135 \mathrm{~K}$, the BSR profile of $128 \mathrm{~K}$ is also modeled over a period of $\sim 11 \mathrm{~h}$, in order to obtain the BSR values for both cases $(135 \mathrm{~K}$ and $128 \mathrm{~K})$ at the same time. Over an 11 -h period the BSR profile at temperature of $128 \mathrm{~K}$ reaches a value of $\sim 5.5$ (Fig. 1a, red dotted line), which is smaller compared to the $135 \mathrm{~K}$ case. The layer thickness almost doubled compared to $\sim 3 \mathrm{~km}$ thickness of the $135 \mathrm{~K}$ case with a peak at $81 \mathrm{~km}$.

The $\pm 5 \%$ changes in temperature are of the order of $14 \mathrm{~K}$ for the selected "base-line" temperature profile (135 K). The magnitude of such variations is comparable, although in the lower range to the temperature fluctuations, which can be induced by upward propagation and breaking of gravity waves, often observed in the upper mesosphere and the mesopause region.

Figure $1 \mathrm{~b}$ shows the variability of BSR with respect to water vapour variations. The background temperature is kept constant at the "base-line" case ( $135 \mathrm{~K}$, blue line) while the same percentage changes of $\pm 5 \%$ as in the temperature test are applied to the background water vapour. Increasing the water vapour mixing ratio by $5 \%$, the BSR is increased by $13 \%$ (black line). A 5\% decrease in the water vapour mixing ratio (Fig. 1b, the red line) leads to practically a $10 \%$ change in the BSR. Accounting for the small water vapour mixing ratios observed in the upper mesosphere, the effect of $\pm 5 \%$ variations in the water vapour profile applied to the "base-line" case fall within the range of experimental noise and model accuracy.

In order to account for more realistic cases of water vapour fluctuations in the region of the upper mesosphere, we allow for variations of \pm 1 ppmv and \pm 2 ppmv on the "base-line" case water vapour profile. Figure 2 illustrates the variability of BSR in the case of \pm 1 ppmv and \pm 2 ppmv variations in the water vapour mixing ratios, which are more likely to occur in the real atmosphere, due to horizontal and vertical transport, as well as, atmospheric tides. In both cases the blue line corresponds to the "base-line" case $(135 \mathrm{~K}, 4.7 \mathrm{ppmv}$ at the mesopause region), the black line represents an increase of 1 ppmv ( 2 ppmv), while the red line corresponds to a decrease of 1 ppmv ( 2 ppmv) in the background water vapour mixing ratio, respectively. The results show that there is a 

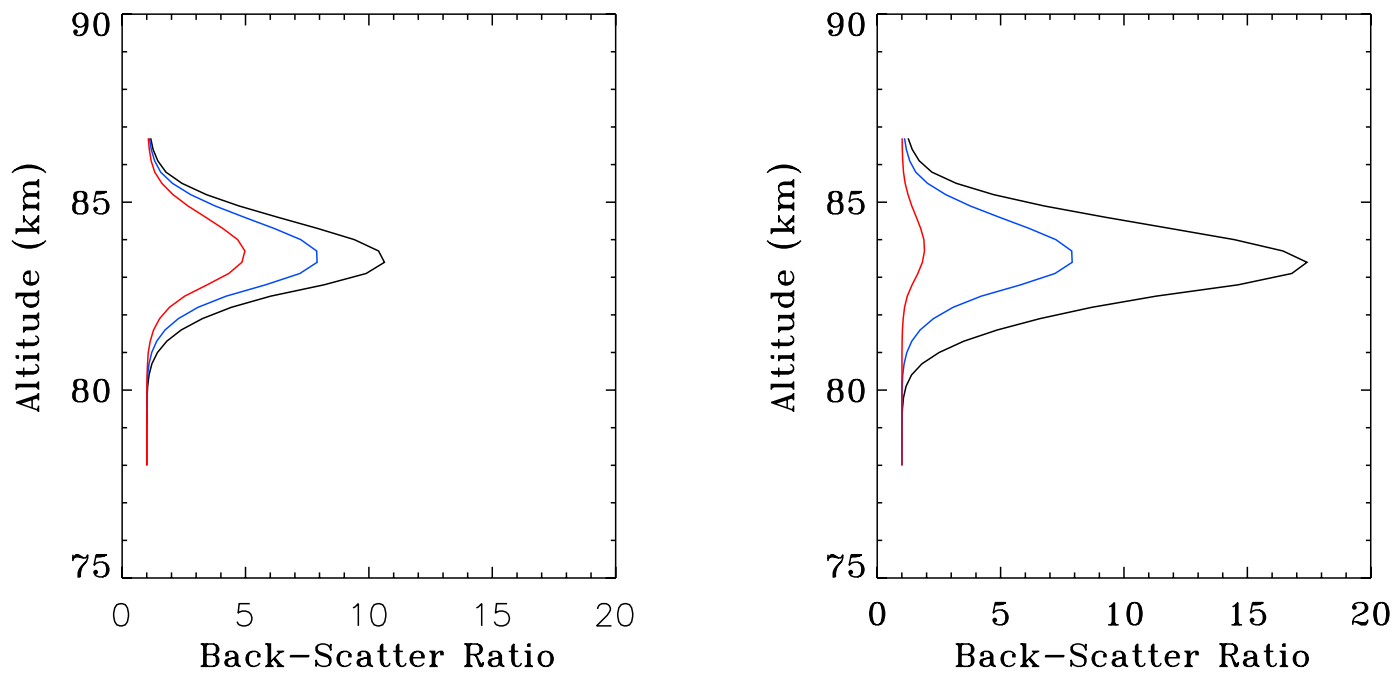

Fig. 2. BSR variability for temperature of $135 \mathrm{~K}$ and changes of the water vapour mixing ratio as follows: (a) \pm 1 ppmv; (b) \pm 2 ppmv. The base-line case, $T=135 \mathrm{~K}$ for water vapour mixing ratio of $4.7 \mathrm{ppmv}$ is given by the blue line; the case for water vapour mixing ratio increase is given by the black line, while the case for water vapour mixing ratio decrease is given by the red line.

$31 \%$ increase in the BSR in the case of a 1 ppmv increase in the background water vapour mixing ratio (Fig. 2a), while the BSR decreases by about the same percentage (37.6\%) in the case of a 1 ppmv decrease in the background water vapour. For the case where there is a change of a \pm 2 ppmv the BSR increases by a factor of 2 reaching the value of $\sim 17$. Decreasing the ambient water vapour by 2 ppmv, leads to a BSR decrease by a factor of 4 , reaching the value of 2 (Table 1 ).

Figure 3a-d gives the time evolution diagrams of the BSR from a "base-line" case over a time period of $36 \mathrm{~h}$ for all cases considered. Figure 3 a shows the "base-line" case ( $135 \mathrm{~K}$ and $4.7 \mathrm{ppmv}$ ), while Fig. $3 \mathrm{~b}$ presents the "baseline" temperature case (at $135 \mathrm{~K}$ ) with the $5 \%$ increase in the ambient water vapour. Figure $3 \mathrm{c}$ illustrates the $5 \%$ reduction in the ambient temperature ( $128 \mathrm{~K}$ ) (with the "baseline" water vapour of $4.7 \mathrm{ppmv}$ ), and finally Fig. 3d shows the "base-line" temperature case $(135 \mathrm{~K})$ with the $5 \%$ reduction in the ambient water vapour. As can be seen, the BSRs increase throughout the model simulations until reaching a maximum value of about 16 (for the "base-line" case, $135 \mathrm{~K}$ and $4.7 \mathrm{ppmv}$ ), 19 (for the 5\% increase in the water vapour and temperature of $135 \mathrm{~K}$ ), 18.5 (for temperature of $128 \mathrm{~K}$ and water vapour of $4.7 \mathrm{ppmv}$ ) and 14 (for the $5 \%$ decrease in the water vapour and temperature of $135 \mathrm{~K}$ ), respectively. The results in Fig. 3a-c are for the same ambient temperature profile, with the mesopause temperature of $135 \mathrm{~K}$ indicating that the super-saturation region, the lifetime of the modelled PMC and the general characteristics of PMCs (e.g. layer thickness and peak altitude) are expected to be approximately the same. Thus, for a mesopause temperature of $135 \mathrm{~K}$ and $\pm 5 \%$ changes in the "base-line" water vapour mixing ratio of 4.7 ppmv, (Fig. 3a-c) a maximum BSR is achieved after $24 \mathrm{~h}$ of particle growth. However, the difference in the maximum
Table 1. Sensitivity of BSR to changes in the background temperature and water vapour abundances.

\begin{tabular}{|c|c|c|c|c|}
\hline \multirow{2}{*}{ BSR change } & \multirow{2}{*}{\multicolumn{2}{|c|}{$\begin{array}{c}5 \% T_{\min }, \text { increase } \\
\text { N/A }\end{array}$}} & \multirow{2}{*}{\multicolumn{2}{|c|}{$\begin{array}{c}5 \% T_{\min }, \text { decrease } \\
37.5 \%\end{array}$}} \\
\hline & & & & \\
\hline \multirow{4}{*}{ BSR change } & \multicolumn{2}{|c|}{$5 \% \mathrm{H}_{2} \mathrm{O}$ increase } & \multicolumn{2}{|c|}{$5 \% \mathrm{H}_{2} \mathrm{O}$ decrease } \\
\hline & \multicolumn{2}{|c|}{$12.5 \%$} & \multicolumn{2}{|c|}{$6.3 \%$} \\
\hline & $+1.0 \mathrm{ppmv}$ & $-1.0 \mathrm{ppmv}$ & $+2.0 \mathrm{ppmv}$ & $-2.0 \mathrm{ppmv}$ \\
\hline & $31 \%$ & $38 \%$ & $200 \%$ & $>300 \%$ \\
\hline
\end{tabular}

BSR value results from the different amount of available water vapour in the region. An increased water vapour leads to the formation of larger particle sizes, hence the larger BSR value compared to Fig. 3a and vice versa. The only case with a monotonous increase in the BSR over the model simulation period is for $T=128 \mathrm{~K}$ where the ambient temperature has been decreased from its "base-line" case, thus broadening the region of the super-saturation. Therefore, the "base-line" water vapour of $4.7 \mathrm{ppmv}$ is deposited over a larger population of condensational nuclei, leading to the formation of more ice particles with smaller sizes. As a result, the time required for the cloud layer to reach its maximum BSR becomes longer.

\section{Results and discussion}

The first step in the model simulations begins with the initialization of the CARMA model with a profile of water vapour mixing ratios in the altitude range $70-90 \mathrm{~km}$. As in 
(a) BSR Time Evolution

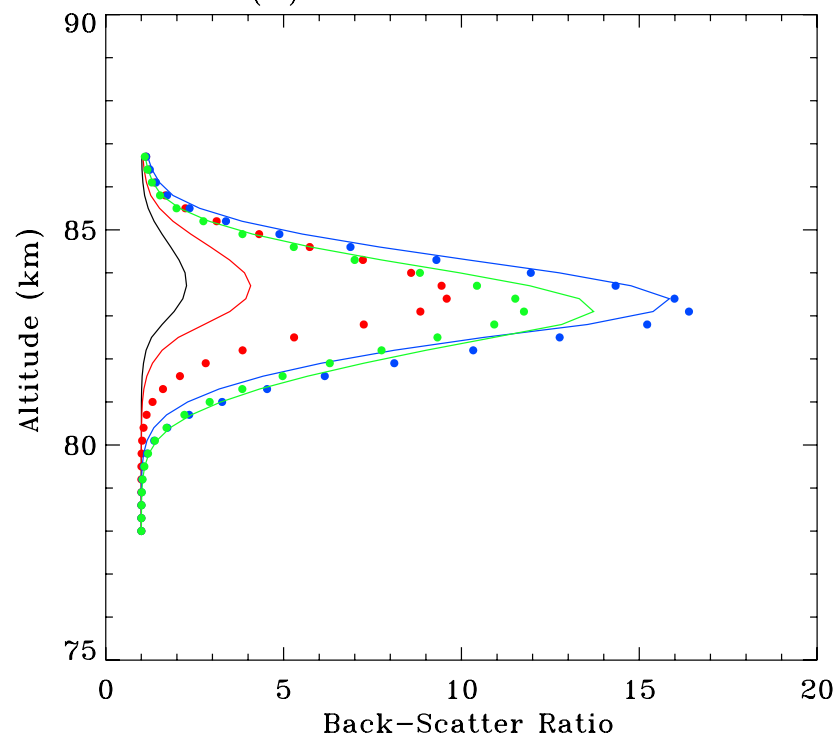

(c) BSR Time Evolution

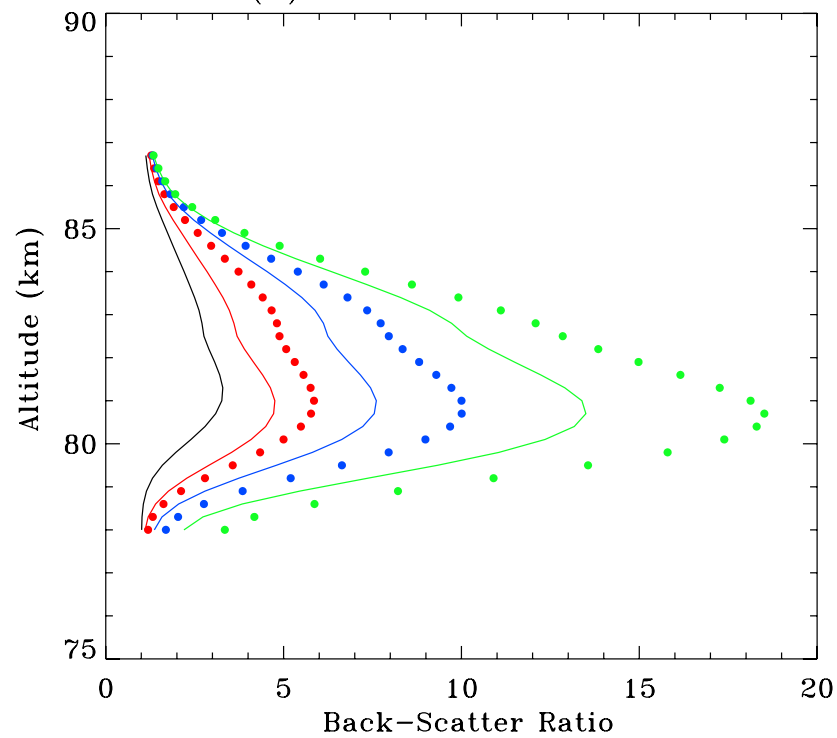

(b) BSR Time Evolution

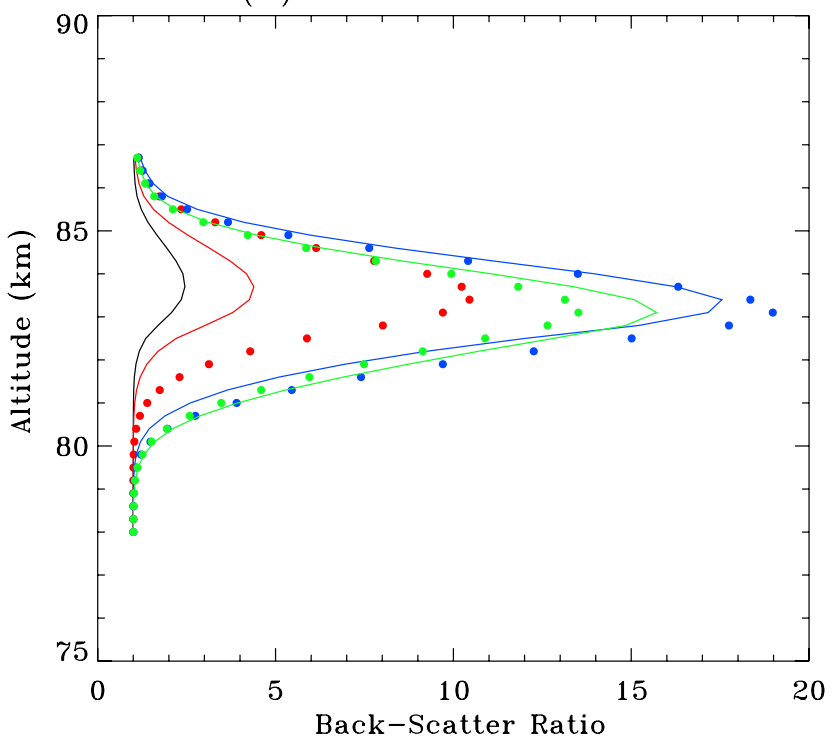

(d) BSR Time Evolution

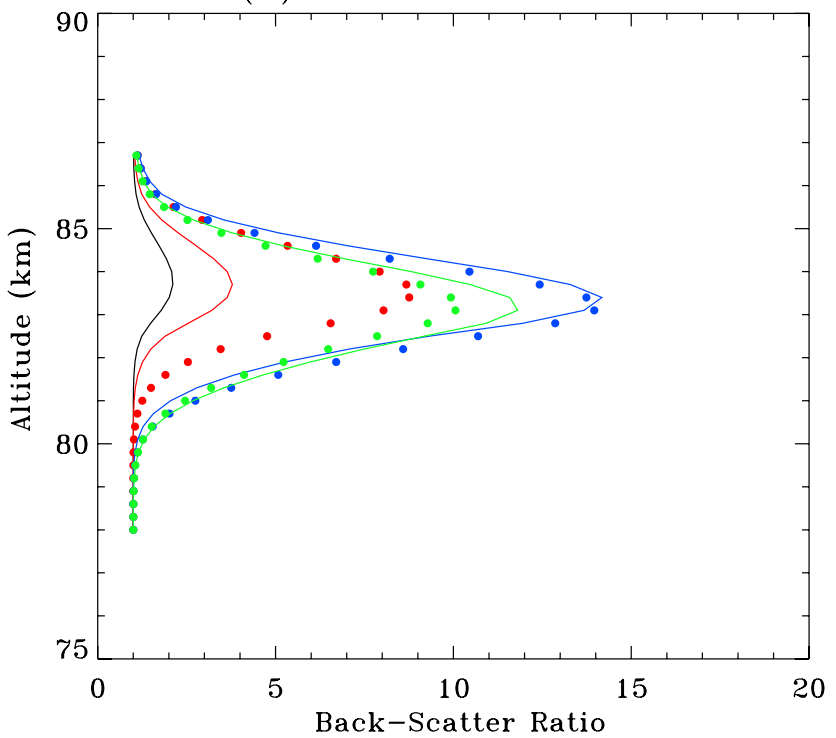

Fig. 3. Sensitivity tests - BSR time evolution at: (a) $135 \mathrm{~K}$, "base-line" case, with water vapour mixing ratio kept constant; (b) base-line temperature at $135 \mathrm{~K}$, water vapour mixing ratio increased by $5 \%$; (c) $128 \mathrm{~K}, 5 \%$ decrease in temperature from "base-line" while water vapour is kept constant at $4.7 \mathrm{ppmv}$; (d) $5 \%$ decrease in water vapour mixing ratio, temperature kept constant at $135 \mathrm{~K}$. Simulation time after start: $3 \mathrm{~h}$ (black); $6 \mathrm{~h}$ (red, solid line), $12 \mathrm{~h}$ (red, dotted line); $18 \mathrm{~h}$ (blue, solid line); $24 \mathrm{~h}$ (blue, dotted line); $30 \mathrm{~h}$ (green, solid line), $36 \mathrm{~h}-$ green, dotted line).

the sensitivity test, this "initial" profile is from the HALOE experiment, for lack of other suitable data. Its purpose is just to start the model simulations. As was already mentioned in Sect. 2.4 a mean temperature profile obtained from 15 FS profiles from the end of July and first half of August 1992 at Andoya $\left(69^{\circ} \mathrm{N}, 16^{\circ} \mathrm{E}\right)$ is used for the initialization of the CARMA model simulation for the retrieval of water vapour profiles. This mean temperature profile is considered to represent the mean thermal structure of the summer meso- sphere in early August 1992, the period for which there are also VSR and BSR satellite observations from WINDII at Northern high latitudes. The use of such a mean temperature profile stems primarily from the lack of available HALOE observational data during that period. In addition, this excludes the possibility for any potential bias in the retrieved HALOE v. 19 temperature profiles to be propagated throughout the model simulations since the HALOE v. 19 measurements of water vapour mixing ratios were found to be biased 
(a) Volume scattering rate

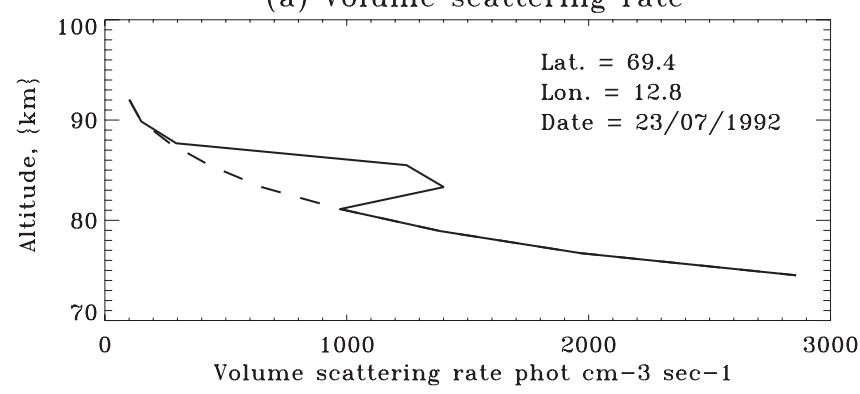

(c) Volume scattering rate

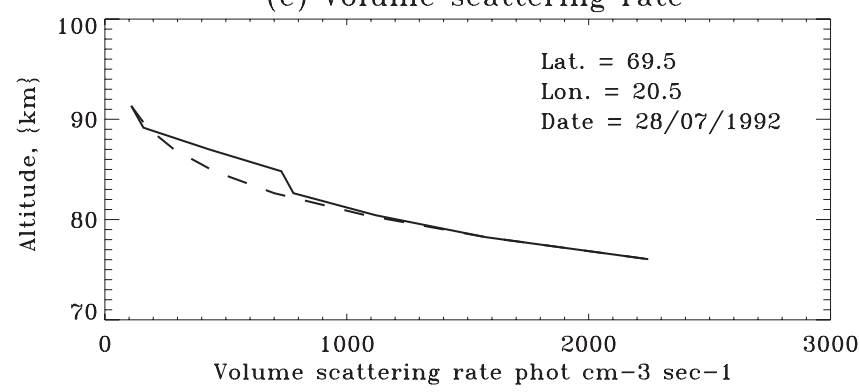

(f) Volume scattering rate

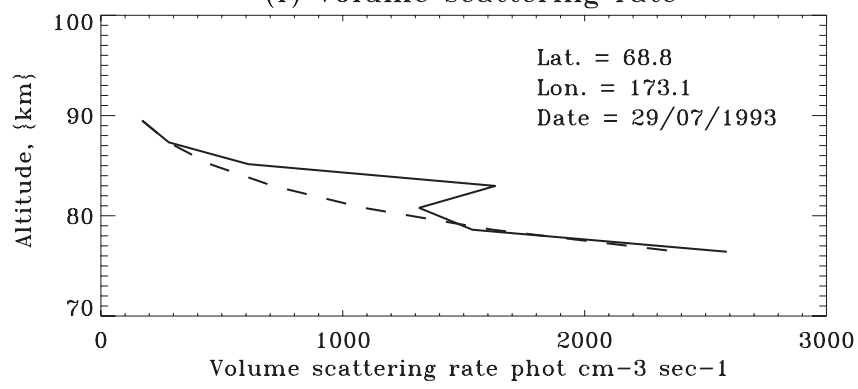

(b) Volume scattering rate

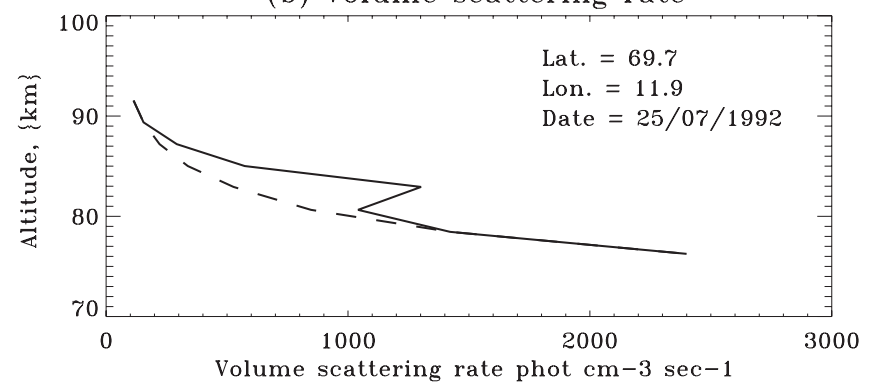

(e) Volume scattering rate

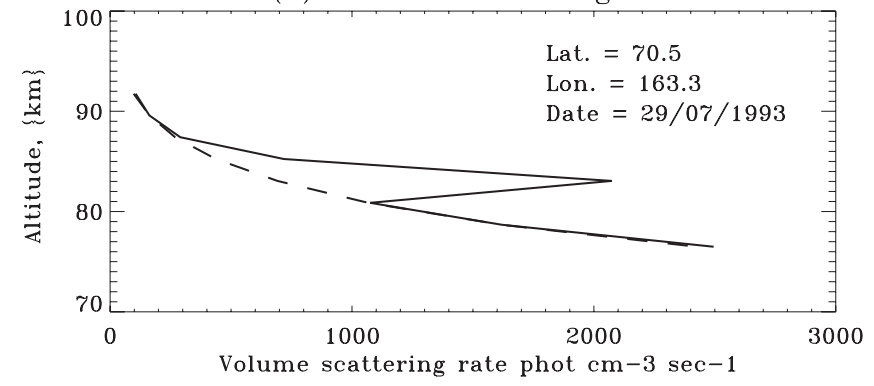

(d) Volume scattering rate

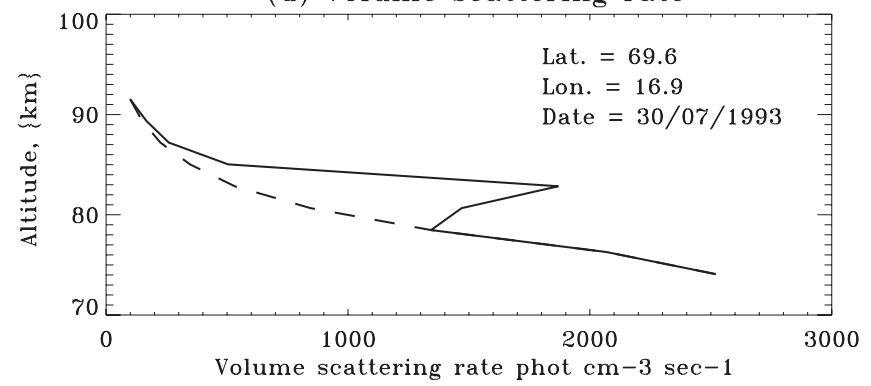

Fig. 4. (a-f) The vertical profiles of the volume scattering radiances in the presence of PMC, used in the model simulations of the BSR (solid line). The volume Rayleigh scattering radiances for a cloud-free atmosphere are given by a dashed line.

and overestimated in the presence of PMC in the upper mesosphere (70-90 km) (McHugh, 2005; McHugh et al., 2006). The model is run and the water vapour mixing ratio is adjusted until there is a match between the modelled and observed BSRs. The adjustment of the water vapour mixing ratio profile is carried out by scaling down the initial water vapour profile in steps of $0.2 \mathrm{ppmv}$, assuming that the scaled water vapour vertical profiles preserve the shape of the initial one. In an attempt to validate the approach described herein, it is crucial to examine the amount of water vapour required to produce the PMCs observed. Therefore, this simplified technique of scaling the initial profile serves the purpose of providing basic information on the water vapour abundance in the vicinity of the PMCs. Each time the water vapour profile is scaled down, the CARMA model is run until a satisfactory match between the model and observed BSR is obtained. In doing so, the modelled and observed BSR profiles are first compared against each other based on their shape in terms of vertical thickness and peak altitude $(\sim 3 \mathrm{~km}$ and
$82-84 \mathrm{~km}$, respectively). Next, the percentage difference between the observed and modelled BSR profiles are calculated at the vicinity of the ice-particle layer peak altitude throughout the model simulations. When the difference between the observed and modelled BSR values is the smallest, the modelled BSR profile is accepted. The BSR percentage difference at the vicinity of the peak altitude ranges between $5 \%$ and $10 \%$. Therefore, the modelled BSR profiles not only have to produce the observed BSR values in the vicinity of PMCs, but also the BSR profiles which produce an ice particle layer of the same properties as the observed.

The results of the model simulations are in good agreement with the observed profiles with respect to the peak altitude of the PMC; however, the vertical extent of the modelled PMC layer often appears slightly broader than the observations. The time elapsed since the beginning of the model simulations is recorded, and the water vapour mixing ratio at the time when $\frac{R^{\prime}}{R} \approx 1$ is considered as the state of the ambient atmosphere in the presence of a PMC. Figure 4 presents 
(a) BSR vertical profile

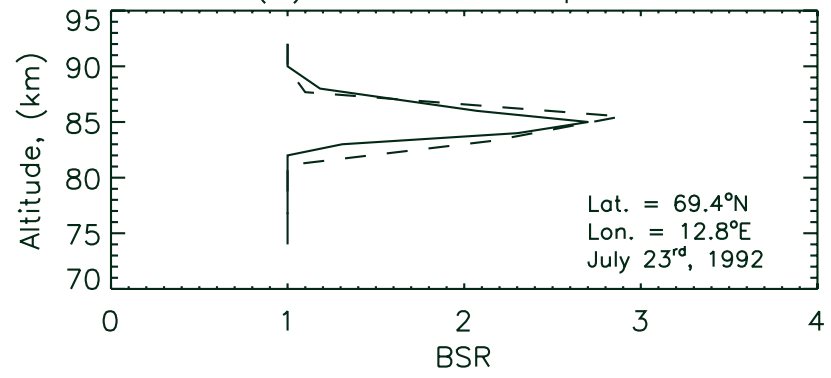

(c) BSR vertical profile

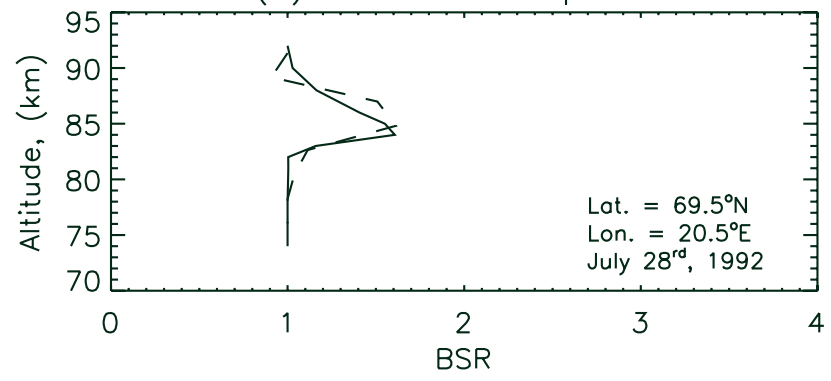

(e) BSR vertical profile

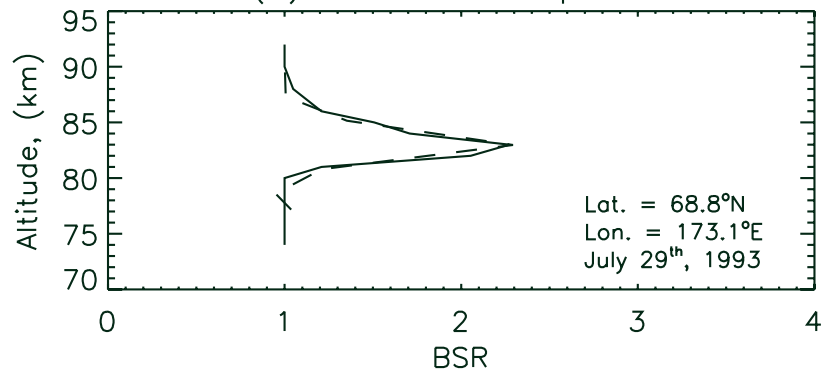

(b) BSR vertical profile

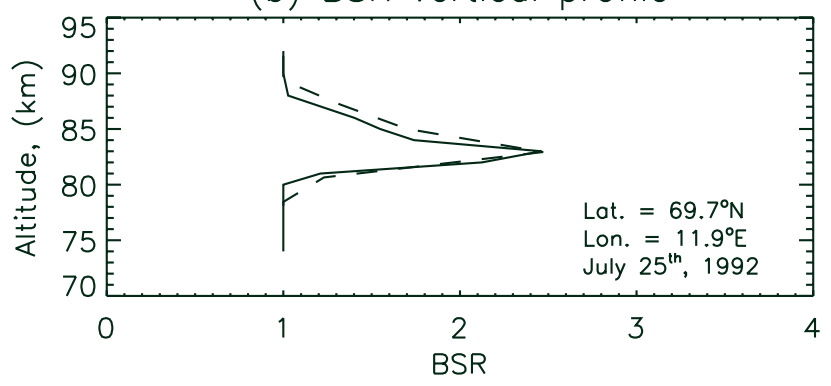

(d) BSR vertical profile

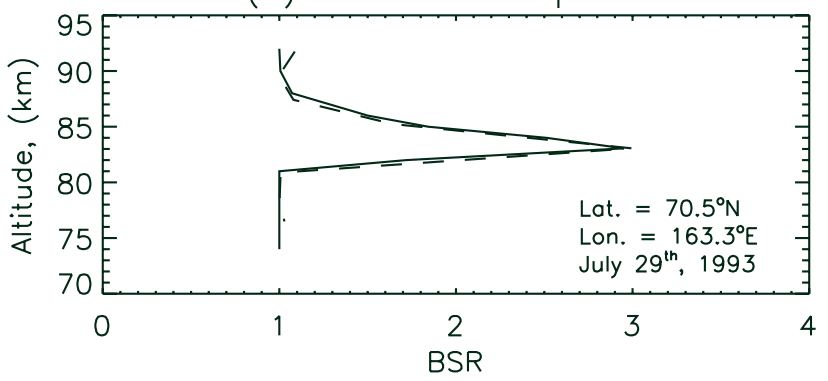

(f) BSR vertical profile

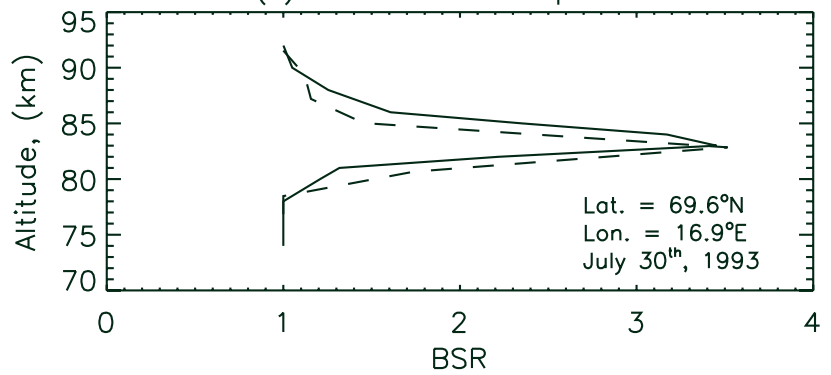

Fig. 5. (a-f) The modelled and observed BSR profiles according to the WINDII data. The solid and dashed lines give the modelled and the observed BSR, respectively.

six of the VSR profiles observed by the WINDII instrument at the end of July for the years 1992 (left) and 1993 (right), superimposed on the background Rayleigh cloud-free VSR profile. Figure 5 presents the observed (dashed line) and modelled (solid line) vertical profiles of the BSR for each case considered, obtained for a simulation period set to $48 \mathrm{~h}$.

According to these model results, during the formation of the ice particle layer there is redistribution of the water vapour content leading to a steep decrease in the water vapour concentration in the region above $82 \mathrm{~km}$. Without influx of condensation nuclei from above following the initial input, and no vertical transport of water vapour the only motion the formed particles experience is due to the gravitational sedimentation and eddy diffusion. Thus, what is modelled and seen is a snapshot of the PMC's BSRs, and what might have been the content of water vapour and temperature in the upper mesosphere at that moment. The region, in which iced particles form and grow, indicates the so-called freeze-drying effect of the upper mesosphere in the case of a PMC formation. On the other hand, an increased amount of water vapour mixing ratio is observed below $82 \mathrm{~km}$, as a result of the iced particles sublimation after falling out of the region of super-saturation. As the modelled PMCs from the WINDII observations considered are relatively weak (BSR of 3-4) no substantial changes in the water vapour mixing ratio is expected below the cloud base due to sublimation of the sedimenting particles. During the model simulation, the ice particle layer becomes visible ${ }^{3} 20 \mathrm{~h}$ after the beginning of the model simulation. The best match with the observed BSR is obtained after $36 \mathrm{~h}$ from the beginning, thus allowing approximately $16 \mathrm{~h}$ for the particles to grow from being sub-visible to becoming visible, as predicted by Rapp et al. (2002).

\footnotetext{
${ }^{3}$ Defined by an iced particle median radius greater than $20 \mathrm{~nm}$, and a particle number density greater than 100 particles $\mathrm{cm}^{-3}$, von Zahn and Berger (2003).
} 
A review of the results from other model simulations (e.g. Turco et al., 1982; Klostermeyer, 1998; von Zahn and Berger, 2003) indicated that the water vapour mixing ratio adopted in those studies were less than the HALOE v. 19 values used in the model initializations. Recently, water vapour mixing ratios measured by the ACE experiment from 32 cases of spatial and temporal coincidence between HALOE and ACE, yielded 29 of which from July, 2004 near $64^{\circ} \mathrm{N}$ (McHugh et al., 2005) that were smaller than the HALOE v. 19 values by about $40 \%$ at around $83 \mathrm{~km}$ (McHugh et al., 2003, 2006). The new HALOE v. PMC water vapour data for July 2004 at $66^{\circ} \mathrm{N}$, corrected for PMC radiance contamination (McHugh, 2005), were also found to be a factor of 2 smaller than the HALOE (v. 19) values and in a very good agreement with the ACE observations (McHugh, 2005; Hervig, 2006).

In order to verify the proposed approach for estimating the water vapour mixing ratio profiles in the PMC region, a mean water vapour profile derived from the 6 simulated BSR cases is compared with water vapour profiles retrieved from the HALOE (v. 19 and v. PMC), the ACE and the Sub-Millimetre Radiometer (SMR) on the Odin satellite experiments. The results are shown in Fig. 6. The Odin/SMR water vapour profile is the mean profile of all mesospheric measurements taken on 15,19 and 28 July 2005 at altitudes between $65^{\circ} \mathrm{N}$ and $75^{\circ} \mathrm{N}$ (Lossow, 2006).

Both ACE and HALOE (v. PMC) data (Fig. 6, purple dash line and green solid line, respectively) give a water vapour mixing ratio of $\sim 6 \mathrm{ppmv}(5.8-6.3 \mathrm{ppmv})$ at $83 \mathrm{~km}$ compared to a mixing ratio of 4 ppmv at the same altitude derived from the WINDII BSR. The derived WINDII water vapour mixing ratio peaks at about $78-79 \mathrm{~km}$ with a value of 6.8 ppmv compared to the ACE observation of 7.3 ppmv and HALOE v. PMC value of $7.5 \mathrm{ppmv}$ at the same height (McHugh, 2005), and $7.7 \mathrm{ppmv}$ from the Odin/SMR. The derived mixing ratio at $82-83 \mathrm{~km}$ of $4 \mathrm{ppmv}$ is comparable to the model results by Körner and Sonnemann (2001) (3 ppmv), ALOMAR-22 GHz: 3-4 ppmv (Seele and Hartogh, 1999), Odin/SMR at $557 \mathrm{GHz}$ : 5 ppmv (Lossow, 2006) and Odin/SMR OH: 1-7 ppmv (Gattinger et al., 2006), HALOE v. PMC: 5-7 ppmv and ACE: 4-7 ppmv (Hervig, 2006). In all these reports a mixing ratio of 7 ppmv appears to be the upper limit of the water vapour content observed at $83 \mathrm{~km}$ and associated with the presence of PMC. Examining the pattern of the derived water vapour profile, we observe that the present results (Fig. 6, black solid line) agree best with the HALOE v. PMC (green solid line) bellow $80 \mathrm{~km}$ and the ACE (dashed purple line) retrievals in the presence of PMC although our values are smaller and are within the low range of Odin/SMR standard deviation for July 2005 (red solid/dotted lines).

In the simulation process, the cloud age giving rise to the BSR observed by the WINDII was determined to be $36 \mathrm{~h}$ from the beginning of the simulation, which is within Hervig's (2006) estimate of the age of the observed HALOE PMC, determined to be between 24 and $96 \mathrm{~h}$, a result also

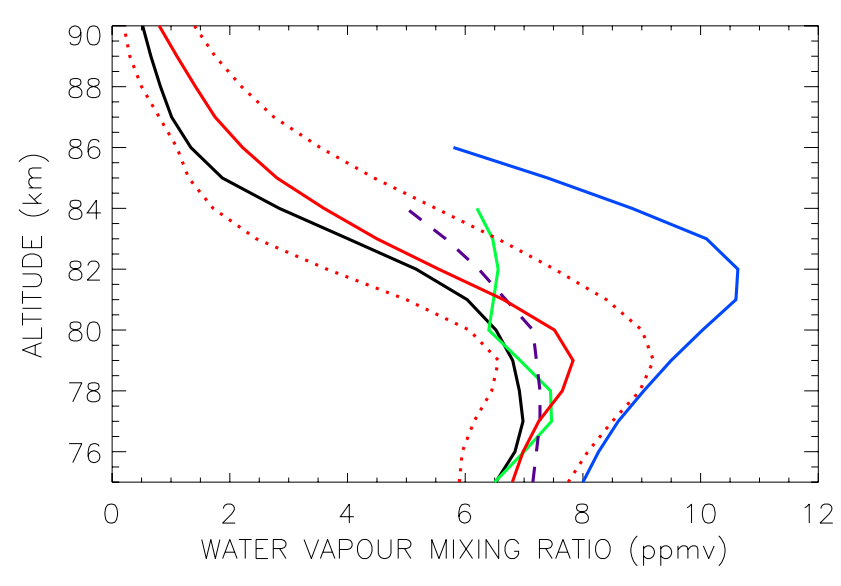

Fig. 6. A comparison between the constructed WINDII mean water vapour profile resulting from the 6 cases for July 1992 and 1993 (black solid line), the mean HALOE (v. 19) water vapour profile for August 1992 and 1993 (blue), the ACE water vapour profile at $66^{\circ} \mathrm{N}$ for July 2004 (green solid line), the HALOE, v. PMC water vapour profile, corrected for PMC contamination (dashed purple line) (McHugh, 2005), and the Odin/SMR mean water vapour profile in the presence of PMCs at $65^{\circ} \mathrm{N}-75^{\circ} \mathrm{N}$, for July 2005 (red solid line). The standard deviation of the Odin/SMR profile in the presence of PMC is given with red dotted lines (adopted from Lossow, 2006).

simulated by the 1-D CARMA model. With the inclusion of transport in the CARMA model the retrieval of water vapour profiles from the observed WINDII BSR is expected to improve, but even in this simplified 1-D version it has been demonstrated that observations of BSR and temperatures can be used to provide a first approximation estimate of the water vapour content in the presence of PMC. In other words, the constructed water vapour profiles may be considered as a proxy of the a priori water vapour profiles which, when subjected to time-dependant microphysical processes such as heterogeneous nucleation, condensational growth/evaporation and sedimentation, produce iced particles, with sufficient number density and size, to account for the BSR observed.

\section{Model errors}

As the retrieval process begins with the assumption of an initial temperature and water vapour profile, errors in these initial profiles inevitably will be propagated into the modelled BSR profiles, and consequently in the WINDII-derived water vapour profiles. To quantify the impact of variations in the initial profiles (temperature and water vapour) on the modelled BSR profiles, a series of sensitivity studies was performed as discussed in Sect. 3. This sensitivity analysis can provide a measure of the BSR model retrieval errors. Assuming the standard deviation of both temperature and water vapour mixing ratios in the upper mesosphere is of the 
order examined in the sensitivity analysis (see Sect. 3). Table 1 represents the percentage error induced in the modelled BSR profiles. It is shown that temperature variations of $\pm 5 \%$ (corresponding to $\sim \pm 7 \mathrm{~K}$ difference) in the initial temperature profile lead to $\sim 38 \%$ (37.5\%) changes in the modelled BSR. However, a $38 \%$ variation in the BSR translates to a $\sim \pm 1$ ppmv in the water vapour profile, as can be seen in Table 1. Further, a bias in the retrieved BSR profiles is introduced as the result of the approach followed in the determination of the theoretical BSR. Specifically, as mentioned in Sect. 2.5, it was assumed that the theoretical BSR profiles are approximated by the total scatter ratio $R^{\prime}$ of the ice particles in the presence of PMCs. Klostermeyer (1998) estimated that this approximation introduces a $\sim 10 \%$ error in the estimation of BSR profiles, which in turn translates to a $\sim 5 \%$ change in the water vapour profiles.

The results presented herein were obtained under two major assumptions for the initialization of the 1-D CARMA model, concerning the particle size distribution and shape, namely that the particle size distribution was log-normal and that the modelled PM iced particles were spherical in shape. While these two simplifying assumptions have been most commonly used in model simulations, recent model work and comparisons with experimental data (e.g. Baumgarten et al., 2002; Eremenko et al., 2005; Hervig, 2006; Rapp et al., 2007) have shown that a Gaussian size distribution and non-spherical iced particles are more consistent with the observations, and should be considered in the modelling of the PMCs. Rapp et al. (2007) have shown that the assumption of spherical particle distribution does not allow a consistent interpretation of available satellite and ground-based observations of PMCs. However, measurements obtained under forward scattering conditions were found to be least sensitive to the assumed particle shape.

At this instance it is not possible to estimate the impact of these new developments on our modelling results. Interestingly, in spite of the crude approximations applied to the present 1-D CARMA model simulations the results obtained appear within the range and comparable with the recent experimental satellite observations. While we recognise the scope for refinement of the model and further development of the approach described herein, the preliminary results obtained are very encouraging.

\section{Conclusions}

The scope of this study lies within the development of an approach for retrieving water vapour profiles in the upper mesosphere and in the vicinity of PMC. The microphysical 1-D CARMA model, satellite volume scattering radiances and temperature measurements and scattering theory of small particles were employed in the retrieval of water vapour mixing ratio profiles. The main objective was to derive "plausible" water vapour profiles from satellite obser- vations and compare the results with other water vapour estimations in order to test the accuracy of the approach presented. Through comparisons, the validity of the satellitederived water vapour profiles was examined with respect to the HALOE (v. 19 \& v. PMC) measurements, the ACE water vapour data, and Odin/SMR water vapour retrievals in the presence of PMCs, as well as assumptions made by other authors in PMC model simulations. The results obtained showed that in spite of the crude first approximation, the WINDII-derived water vapour mixing ratio profiles are realistic, both in terms of the magnitude of water vapour mixing ratios and of its vertical distribution, indicating that information on the BSRs can be used in the retrieval of water vapour mixing ratio. This can also be used as a test for the development of a more elaborate algorithm for the retrieval of water vapour from BSR employing VSR data and with the aid of microphysical models, in which the full range of scattering angles and particle distributions would be accounted for.

Water vapour mixing ratio measurements in the upper mesosphere are difficult to make because of the possible contamination of satellite observations by the presence of these very thin scattering layers (e.g. PMC). The approach presented herein showed that by using scattered radiance observations for the retrieval of water vapour mixing ratios, 1D model simulations can be performed to predict the PMC layer producing the observed BSR using the result as a first approximation in the retrieval of water vapour mixing ratios. State-of-the-art models like CARMA and COMMA/IAP exist for simulations of the PMC particles. The present report has shown how the results obtained compare with other water vapour mixing ratio observations, when only vertical transport is considered using just a 1-D (CARMA) model. The approach described can also be used for the derivation of temperature profiles rather than water vapour mixing ratios. The methodology is the same as the one described for the derivation of water vapour mixing ratio profiles. In this regard, temperature profiles can also be simulated within the PMC region, even if the scattered solar radiances delineate from the Rayleigh-type of the background atmosphere. Rapp and Thomas (2006) have shown that 1-D CARMA can successfully be used if provisions are made for vertical transport by assuming the profile of vertical winds. Including horizontal transport undoubtedly would improve the model simulations of the PMC particles life cycle and their size distribution (upon which the scattering properties of the layer depends). The technique would also improve if the adjustment of the initial water vapour mixing ratio profile was performed using an iteration method (e.g. Chahine method) in the comparison of the observed and simulated BSRs at every altitude of the simulations, rather than applying a scaling factor to the entire profile. In conclusion, the aim of this study was to examine the possibility of introducing a theoretical approach of estimating atmospheric parameters, like water vapour mixing ratios and temperature, using satellite observations when these parameters are not observed directly. The results obtained 
showed that in spite of its preliminary stage and crude approximations, the approach proposed was successful in retrieving water vapour mixing ratio profiles and demonstrated the method's capabilities. However, further work is needed to incorporate recent model and experimental data and therefore, the results presented should be considered preliminary.

Acknowledgements. The authors dedicate this paper to the memory of Diane Michelangeli, who passed away on 30 August 2007. We thank the Editor and the two reviewers for their constructive comments and helpful suggestions. This study has been supported by a research grant from the Natural Science and Engineering Research Council of Canada.

Topical Editor U.-P. Hoppe thanks two anonymous referees for their help in evaluating this paper.

\section{References}

Backhouse, T. W.: The luminous cirrus cloud of June and July, Meteorol. Mag., 20, 133, 1885.

Bailey, S. M., Merkel, A. W., Thomas, G. E., and Carstens, J. N.: Observations of polar mesospheric clouds by the Student Nitric Oxide Explorer, J. Geophys. Res., 110, D13203, doi:10.1029/2004JD005422, 2005.

Baumgarten, G., Fricke, K. H., and von Cossart, G.: Investigation of the shape of noctilucent cloud particles by polarization lidar techniques, Geophys. Res. Lett., 29(13), 1630, doi:10.1029/2001GL013877, 2002.

Benze, S., Randall, C. E., DeLand, M. T., Thomas, G. E., Rusch, D. W., Bailey, S. M., Russell III, J. M., McClintock, W., Merkel, A. V., and Jeppesen, C.: Comparison of Polar Mesospheric Cloud Measurements from the Cloud Imaging and Particle Size Experiment and the Solar Backscatter Ultraviolet Instrument in 2007, J. Atmos. Solar-Terr. Phys., in press, doi:10.1016/j.jastp.2008.07.014, 2009.

Bernath, P. F.: The Atmospheric Chemistry Experiment (ACE): An Overview, Spectroscopy from Space, Kluwer Academic Publishers, 147-161, 2001.

Bernath, P. F., McElroy, C. T., Abrams, M. C., et al.: Atmospheric Chemistry Experiment (ACE): Mission overview, Geophys. Res. Lett., 32, L15S01, doi:10.1029/2005GL022386, 2005.

Bovensmann, H., Burrows, J. P., Buchwitz, M., et al.: SCIAMACHY: mission objectives and measurement modes, J. Atmos. Sci., 56(2), 127-150, 1999.

Carleer, M. R., Boone, C. D., Walker, K. A., Bernath, P. F., Strong, K., Sica, R. J., Randall, C. E., Vömel, H., Kar, J., Höpfner, M., Milz, M., von Clarmann, T., Kivi, R., Valverde-Canossa, J., Sioris, C. E., Izawa, M. R. M., Dupuy, E., McElroy, C. T., Drummond, J. R., Nowlan, C. R., Zou, J., Nichitiu, F., Lossow, S., Urban, J., Murtagh, D., and Dufour, D. G.: Validation of water vapour profiles from the Atmospheric Chemistry Experiment (ACE), Atmos. Chem. Phys. Discuss., 8, 4499-4559, 2008, http://www.atmos-chem-phys-discuss.net/8/4499/2008/.

Collis, R. T. H. and Russell, P. B.: Lidar measurement of particles and gases by elastic backscattering and differential absorption, in: Laser Monitoring of the Atmosphere, edited by: Hinkley, E. D., Springer-Verlag, Berlin, 1976.

Debrestian, D. J., Lumpe, J. D., Shettle, E. P., et al.: An analysis of POAM II solar occultation observations of polar mesospheric clouds in the Southern Hemisphere, J. Geophys. Res., 102(D2), 1971-1981, 1997.

DeLand, M. T., Shettle, E. P., Thomas, G. E., and Olivero, J. J.: Solar backscattered ultraviolet (SBUV) observations of polar mesospheric clouds (PMCs) over two solar cycles, J. Geophys. Res., 108(D8), 8445, doi:10.1029/2002JD002398, 2003.

Donahue, T. M., Guenther, B., and Blamont, J. E.: Noctilucent clouds in daytime: Circumpolar particulate layers near the summer mesopause, J. Atmos. Sci., 36, 515-517, 1972.

Eremenko, M. N., Petelina, S. V., Zasetsky, A. Y., Karlsson, B., Rinsland, C. P., Llewellyn, E. J., and Sloan, J. J.: Shape and composition of PMC particles derived from satellite remote sensing measurements, Geophys. Res. Lett., 32, L16S06, doi:10.1029/2005GL023013, 2005.

Evans, W. F. J., Laframboise, K. R., Sine, R., Wiens, H., and Shepherd, G. G.: Observations of polar mesospheric clouds in summer, 1993 by the WINDII instrument on UARS, Geophys. Res. Lett., 22, 2793-2796, 1995.

Gadsden, M. and Schröder, W.: Noctilucent Clouds, 165 pp., Springer, New York, 1989.

Gattinger, R. L., Boone, C. D., Walker, K. A., Degenstein, D. A., Bernath, P. F., and Lllewellyn, E. J.: Comparison of OdinOSIRIS OH $\mathrm{A}^{2} \Sigma^{+}-\mathrm{X}^{2} \Pi 0-0$ mesopsheric observations and ACE-FTS water vapour observations, Geophys. Res. Lett., 33, L15808, doi:10.1029/2006GL026425, 2006.

Gumbel, J., Siskind, D. E., Witt, G., Torkar, K. M., and Friedrich, M.: Influences of ice particles on the ion chemistry of the polar summer mesosphere, J. Geophys. Res., 108(D8), 8436, doi:10.1029/2002JD002413, 2003.

Hedin, J., Gumbel, J., Khaplanov, M., Witt, G., and Stegman, J.: Optical studies of noctilucent clouds in the extreme ultraviolet, Ann. Geophys., 26, 1109-1119, 2008,

http://www.ann-geophys.net/26/1109/2008/.

Hervig, M. E., Thompson, R. E., McHugh, M., Gordley, L. L., Russell, J. M., and Summers, M. E.: First confirmation that water ice is the primary component of polar mesospheric clouds, Geophys. Res. Lett., 28, 971-974, 2001.

Hervig, M., McHugh, M., and Summers, M. E.: Water vapor enhancement in the polar summer mesosphere and its relationship to polar mesospheric clouds, Geophys. Res. Lett., 30(20), 2041, doi:10.1029/2003GL018089, 2003.

Hervig, M.: PMC Particle Size from 14 Years of HALOE Observations, Presentation at the CAWSES Ice Layer Workshop, Kuhlungsborn, available at: http://gwest.gats-inc.com/haloe_pmc_ project/HALOE_Vpmc_publications.html, Germany, May 2006.

Hervig, M. E., Gordley, L. L., Stevens, M., Russell, J. M., and Bailey, S.: SOFIE PMC measurements during the northern summer of 2007, J. Atmos. Solar-Terr. Phys., in press, doi:10.1016/j.jastp.2008.07.09, 2009.

Hunten, D. M., Turco, R. P., and Toon, O. B.: Smoke and dust particles of meteoric origin in the mesosphere and stratosphere, J. Atmos. Sci., 37, 1342-1357, 1980.

Jensen, E. J. and Thomas, G. E.: A growth-sedimentation model of polar mesospheric clouds: Comparison with SME measurements, J. Geophys. Res., 93, 2461-2473, 1988.

Jensen, E. J., Thomas, G. E., and Toon, O. B.: On the diurnal variation of noctilucent clouds, J. Geophys. Res., 94(D12), 1469314702, 1989.

Jesse, O.: Auffallende Abenderscheinungen am Himmel, Meteorol. 
Z., 2, 311-312, 1885.

Jesse, O.: Die Beobachtung der leuchtenden Wolken (Observations of noctilucent clouds), Meteor. Z., 4, 179-181, 1887.

Klostermeyer. J.: A simple model of the ice particle size distribution in noctilucent clouds, J. Geophys. Res., 103(D22), 2874328752, 1998.

Körner, U. and Sonnemann, G. R.: Global three-dimensional modelling of the water vapor concentration of the mesospheremesopause region and implications with respect to the noctilucent cloud region, J. Geophys. Res., 106(D9), 9639-9652, 2001.

Lossow, S.: Odin SMR measurements of mesospheric water vapour and its redistribution by NLC, 3rd Limb Workshop, Montreal, http://osirus.usask.ca/osiris/limbworkshopweb/ presentations/Lossow.pdf, 2006.

Lübken, F. J.: Thermal structure of the Arctic summer mesosphere, J. Geophys. Res., 104(D8), 9135-9149, 1999.

Lübken, F.-J.: Nearly zero temperature trend in the polar summer mesosphere, Geophys. Res. Lett., 27, 3603-3606, 2000.

Lübken, F. J., Zecha, M., Höffner, J., and Röttger, J.: Temperatures, polar mesosphere summer echoes, and noctilucent clouds over Spitsbergen ( $78^{\circ}$ N), J. Geophys. Res., 109, D11203, doi:10.1029/2003JD004247, 2004.

McHugh, M., Hervig, M., Magill, B., Thompson, R. E., Remsberg, E., Wrotny, J., and Russell, J.: Improved mesospheric temperature, water vapor, and polar mesospheric cloud extinctions from HALOE, Geophys. Res. Lett., 30(8), 1440, doi:10.1029/2002GL016859, 2003.

McHugh, M., Magill, B., Walker, K. A., Boone, C. D., Bernath, P. F., Russell, J. M.: Comparison of atmospheric retrievals from ACE and HALOE, Geophys. Res. Lett., 32, L15S10, doi:10.1029/2005GL022403, 2005.

McHugh, M.: ACE-HALOE Comparisons. GATS Inc., http://bernath.uwaterloo.ca/ASSFTS/Media/ASSFTS\%

20Presentations/pdfPres/McHugh.pdf, 2005.

Murtagh, D. P., Frisk, U., Merino, F., Ridal, M., Jonsson, A., Stegman, J., Witt, G., Eriksson, P., Jiménez, C., Mégie, G., de la Noë, J., Ricaud, P., Baron, P., Pardo, J. R., Hauchecorne, A.,Llewellyn, E. J., Degenstein, D. A., Gattinger, R. L., Lloyd, N. D., Evans, W. F. J., McDade, I. C., Haley, C. S., Sioris, C., von Savigny, C., Solheim, B. H., McConnell, J. C., Strong, K., Richardson, E. H., Leppelmeier, G. W., Kyrölä, E., Auvinen, H., and Oikarinen, L: An overview of the Odin atmospheric mission, Can. J. Phys., 80, 309-319, 2002.

Olivero, J. J. and Thomas, G. E.: Climatology of Polar Mesospheric Clouds, J. Atmos. Sci., 43, 1263-1274, 1986.

Petelina, S. V., Llewellyn, E. J., Degenstein, D. A., and Lloyd, N. D.: Odin/OSIRIS limb observations of Polar Mesopsjeric Clouds in 2001-2003, J. Atmos. Solar-Terr. Phys., 68, 42-55, 2006.

Rapp, M., Lübken, F.-J., Müllemann, A., Thomas, G. E., and Jensen, E. J.: Small-scale temperature variations in the vicinity of NLC: Experimental and model results, J. Geophys. Res., 107(D19), 1-20, 2002.

Rapp, M. and Thomas, G. E.: Modelling the microphysics of mesospheric ice clouds: Assessment of current capabilities and basic sensitivity, J. Atmos. Sol.-Terr. Phys., 68, 517-744, 2006.

Rapp, M., Thomas, G. E., and Baumgarten, G.: Spectral properties of mesospheric ice clouds: Evidence for nonspherical particles, J. Geophys. Res., 112, D03211, doi:10.1029/2006JD007322, 2007.
Reber, C. A., Trevathan, E. C., Neal, J. R., et al.: Upper Atmospheric Research Satellite (UARS) mission, J. Geophys. Res., 98, 10643-10647, 1993.

Reid, G. C.: The nucleation and growth of ice particles in the upper mesosphere, Adv. Space Res., 20, 1285-1291, 1997.

Russell III, J. M., Gordley, L. L., and Drayson, J. H.: The Halogen Occultation Experiment, J. Geophys. Res., (ISSN 0148-0227), 98(D6), 10777-10797, 1993.

Russell III, J. M., Bailey, S. M., Horányi, M., Gordley, L. L., Rusch, D. W., Hervig, M. E, Thomas, G. E., Randall, C. E., Siskind, D. E., Stevens, M. H., Summers, M. E., Taylor, M. I., Englert, C. R., Espy, P. J., McClintock, W. E., and Merkel, A. V.: Aeronomy of Ice in the Mesosphere (AIM): Overview and early science results, J. Atmos. Solar-Terr. Phys., in press, doi:10.1016/j.jastp.2008.08.011, 2009.

Schmidlin, F., Lee, H., and Michel, W.: The inflatable sphere: A technique for the accurate measurement of middle atmosphere temperatures, J. Geophys. Res., 96, 22673-22682, 1991.

Seele, C. and Hartogh, P.: Water vapor of the polar middle atmosphere: Annual variation and summer mesosphere conditions as observed by ground-based microwave spectroscopy, Geophys. Res. Lett., 26, 1517-1520, 1999.

Shepherd, G., Thuillier, G., Gault, W. A., et al.: WINDII, the Wind Imaging Interferometer on the Upper Atmosphere Research Satellite, J. Geophys. Res., 98, 10725-10750, 1993.

Shepherd, M. G., Reid, B., Zhang, S., Solheim, H. B., Shepherd, G. G., Wickwar, B. V., and Herron, P. J.: Retrieval and validation of mesospheric temperatures from WINDII Imaging Interferometer observations, J. Geophys. Res., 106(A11), 24813-24829, 2001.

Thomas, G. E.: Mesospheric clouds and the physics of the mesopause region, Rev. Geophys., 29, 553-575, 1991.

Thomas, G. E.: Climatology of polar mesospheric clouds: Interannual variability and implications for long-term trends, in: The Upper Mesosphere and Lower Thermosphere: A Review of Experiment and Theory, Geophys. Mongr. Ser., vol. 87, edited by: Johnson, R. M. and Killeen, T. E., 185-200, AGU, Washington, D.C., 1995.

Thomas, G. E. and Olivero, J. J.: Climatology of polar mesospheric clouds: 2. Further analysis of Solar Mesosphere Explorer data, J. Geophys. Res., 94(D12), 14673-14681, 1989.

Toon, O. B., Turco, R. P., Hamill, P., Kiang, C. S., and Whitten, R. C.: A one dimensional model describing aerosol formation and evolution in the stratosphere, II. Sensitivity studies and comparison with observations, J. Atmos. Sci., 36, 718-736, 1979.

Toon, O. B., Turco, R. P., Westphal, D., Malone, R., and Liu, M. S.: A multidimensional Model for Aerosols: Description of Computational Analogs, J. Atmos. Sci, 45(15), 2123-2143, 1988.

Turco, P. R., Hamill, P., Toon, O. B., Whitten, R. C., and Luang, C. S.: A one dimensional model describing aerosol formation and evolution in the stratosphere, I. Physical processes and mathematical analogs, J. Atmos. Sci., 36, 699-717, 1979.

Turco, P. R., Toon, B. O., Whitten, C. R., Keesee, G. R., and Hollenbach, D.: Noctilucent clouds: Simulation studies of their genesis, properties and global influences, Planet. Space Sci., 30(11), 1147-1181, 1982.

van de Hulst, H. C.: Light Scattering by Small Particles, John Wiley \& Sons, New York, 1957.

von Cossart, G., Fiedler, J., and von Zahn, U.: Size distribution of NLC particles as described from 3-colour observations of NLC 
by ground-based lidar, Geophys. Res. Lett., 26(11), 1513-1516, 1999.

von Cossart, G., Fiedler, J., von Zahn, U., Hansen, G., and Hoppe, U.-P.: Noctilucent clouds: One- and two-colour lidar observations, Geophys. Res. Lett., 24, 1635-1638, 1997.

von Savigny, C., Kokhanovsky, A., Bovensmann, H., Eichmann, K.-

U., Kaiser, J., Noel, S., Rozanov, A. V., Skupin, J., and Burrows, J. P.: NLC detection and particle size determination: first results from SCIAMACHY on ENVISAT, Adv. Space Res., 34, 951856, 2004.

von Savigny, C., Petelina, S. V., Karlsson, B., Llewellyn, E. J., Degenstein, D. A., Lloyd, N. D., and Burrows, J. P.: Vertical variation of NLC particle sizes from Odin/OSIRIS limb scattering observations, Geophys. Res. Lett., 32, L07806, doi:10.1029/2004GL021982, 2005. von Zahn, U. and Berger, U. : Persistent ice clouds in the midsummer upper mesosphere at high latitudes: Three-dimensional modelling and cloud interactions with ambient water vapour, J. Geophys. Res., 108(D8), 1-18, 2003.

von Zahn, U., Baumgarten, G., Berger, U., Fiedler, J., and Hartogh, P.: Noctilucent clouds and the mesospheric water vapour: the past decade, Atmos. Chem. Phys., 4, 2449-2464, 2004, http://www.atmos-chem-phys.net/4/2449/2004/.

Westley, M. S., Baratta, G. A., and Baragiola, R. A.: Density and index of refraction of water-ice films vapour deposited at low temperature, J. Chem. Phys., 108(8), 3321-3326, doi:10.1063/1.475730, 1998. 